\title{
Electrophysiological features of familial amyloid polyneuropathy in endemic area
}

Minori Kodaira MD, Hiroshi Morita MD, PhD,

Yoshio Shimojima MD, PhD, Shu-ichi Ikeda MD, PhD.

Department of Medicine (Neurology and Rheumatology),

Shinshu University School of Medicine.

3-1-1 Asahi, Matsumoto 390-8621, Japan.

Key words: familial amyloid polyneuropathy, peripheral nerve dysfunction, amyloid, transthyretin, nerve conduction study

Abbreviations: ATTR = amyloidogenic transthyretin, ADM = abductor digiti minimi muscle, $\mathrm{AH}=$ abductor hallucis muscle, $\mathrm{CMAP}=$ compound muscle action potential, $\mathrm{DL}=$ distal latency, FAP = familial amyloid polyneuropathy, MCV = motor nerve conduction velocity, SCV = sensory nerve conduction velocity, SNAP = sensory nerve action potential, Val30Met $=$ methionine is substituted for valine at position 30 .

Corresponding author: H. Morita. Department of Medicine (Neurology and Rheumatology) Shinshu University School of Medicine.

Asahi 3-1-1 Matsumoto, 390-8621, Japan

TEL +81-263-37-2673, FAX +81-263-37-3427

E-mail: hmorita@shinshu-u.ac.jp 


\section{Abstract}

The process of deterioration of peripheral nerve function in familial amyloid polyneuropathy (FAP) with amyloidogenic transthyretin (ATTR) Val30Met has not been systematically evaluated hitherto. We performed nerve conduction studies in 69 patients with FAP with ATTR Val30Met from one of the endemic areas in Japan. Sensory conduction velocity (SCV), motor conduction velocity (MCV), the size of the compound muscle action potential (CMAP), and distal latency (DL) were measured in the ulnar and tibial nerves. SCV was evaluated using the orthodromic method with needle recording electrodes. These electrophysiological parameters were compared with clinical stage of FAP and duration of neuropathy. When subjects noted minimal neuropathic symptoms only in the feet, motor and sensory nerve function in both the hands and feet had already been disturbed. Sensory nerve action potential on the foot disappeared more rapidly than CMAP. CMAP on foot muscle rapidly decreased during the initial 2 years and completely disappeared within 10 years. The duration of illness and deterioration parameters (CMAP of the abductor minimi muscle, MCV and SCV of the ulnar nerve, and DL of both ulnar and tibial nerves) were linearly correlated. CMAP was the most sensitive and reliable parameter to evaluate motor nerve degeneration in FAP. 


\section{Introduction}

Familial amyloid polyneuropathy (FAP) is one form of hereditary generalized amyloidosis with an autosomal dominant trait. The representative type of FAP, which is caused by deposition of amyloid derived from amyloidogenic transthyretin (ATTR) Val30Met (methionine being substituted for valine at position 30), is characterized by progressive polyneuropathy starting in the legs, autonomic failure and extensive visceral organ involvement including heart and kidney [1]. FAP was once considered to be a disease peculiar to endemic areas (Porto in Portugal [2], Skelleftea in Sweden [3], and Arao [4] and Ogawa [5, 6] in Japan), but recent advances in diagnostic techniques have made it possible to find many FAP patients unrelated to these four classic endemic areas [7]. FAP kindreds are now known to exist in many nations worldwide and this disease is a common disorder among hereditary neuropathies [8].

The clinical phenotypes of ATTR type FAP have been shown to vary in different kindreds or individuals with diverse TTR gene mutations [1]. Even in FAP with ATTRVal30Met, the clinical picture is considerably different between patients originating from endemic foci and those with non-endemic origins: the latter group of patients show a late age of onset, male predominance and an obscure family history $[9,10]$. In addition, apparent dissociated sensory loss and serious autonomic dysfunctions, both of which are cardinal clinical features in the former group of patients with an early age of onset, are not usually seen in the latter [10]. An anticipation phenomenon is also observed only in endemic patients [11-14]. It was recently shown that histopathological and electrophysiological 
findings of peripheral nerve lesions differed between the two groups [15-17]. Although genetic, gender and environmental factors, and aging are surmised to be the causes of these differences, the details remain unclear.

An epoch-making therapeutic approach was developed 20 years ago: as the liver produces most of the serum TTR [18], liver transplantation came to be employed for the treatment of FAP patients [19]. It was demonstrated that ATTR disappeared from the serum of FAP patients after this operation and that the progression of peripheral nerve dysfunction in the patients with successful operations undoubtedly stopped [19, 20]. Long-term observation of the transplanted patients has clearly shown that early liver transplantation can improve FAP patients' survival and quality of life [21, 22], with histopathological regression of amyloid deposits in these patients [23]. Moreover, clinical trials of some drugs that prevent the formation of ATTR-derived amyloid fibrils are now ongoing [24]. To precisely evaluate the therapeutic effects of these new approaches in FAP patients, some objective parameters reflecting peripheral nerve function in FAP are necessary.

Objective evaluation of the natural courses of patients with this disease is, therefore, important to clarify the precise mechanism and to evaluate the effect of therapy in ATTRVal30Met type FAP. However, there are few systematic neurophysiological evaluations of this disease, especially in patients with an early onset. In the present study we tried to clarify the electrophysiological features in peripheral neuropathy in an early-onset type of FAP patients with ATTRVal30Met, paying special attention to differences in gender. 


\section{Patients and Methods}

\section{Subjects}

The study was carried out between 1981 and 2009, and 69 patients (34 males and 35 females) diagnosed as having FAP with ATTRVal30Met were examined. All patients originated from Ogawa village [6], one endemic area of this disease in Japan. Between 1981 and 1990 the diagnosis of 15 patients was based on typical clinical manifestations of peripheral somatic and autonomic neuropathy, positive family history, and histopathological demonstration of amyloid deposits on biopsied tissues consisting of gastric and/or rectal mucosa, skin and sural nerve. Additionally, TTR gene analysis of 54 patients was routinely carried out after 1990 as described previously [25, 26]. For the patients before the development of DNA testing, FAP was clinically diagnosed and the mutation of ATTRVal30Met was later confirmed by genetic examinations of their children or siblings who were also included this study. The initial manifestation in all the patients was sensory neuropathic symptoms or dysautonomia. Sensory neuropathic symptoms consisting of altered sensation, prickling numbness, burning or lancinating pain in the legs were the most common initial symptoms (68\%). The remaining 32\% of patients started with dysautonomia including periodic vomiting, severe diarrhea, dysuria, impotence and orthostatic fainting. They followed the typical clinical course of FAP with ATTRVal30Met described previously [6]. We repeated very careful questionnaires several times during their evaluations and defined the onset of neuropathy as the point when the patients first presented the above symptoms. The onset age of neurological symptoms ranged from 19 to 63 years old (35.8 \pm 9.3 years old, mean \pm SD): the average age at onset in 
males was younger than in females (male $33.4 \pm 9.4 \mathrm{y}$, female $38.1 \pm 8.7 \mathrm{y}, \mathrm{p}<0.05$ ).

Neurophysiological study was performed 0.4 to $10(3.6 \pm 2.4)$ years after the onset of neuropathy. According to the clinical stages of FAP proposed by Countinho et al [27], the patients were divided into the four groups (from stage 0 to stage III) summarized in Table 1. However, there were no patients included in stage III at the first evaluation.

All examinations were performed as part of clinical evaluation for care and treatment of the patients, in accordance with the social health insurance laws of Japan. Following the Declaration of Helsinki, the patients gave informed consent to these procedures. This long-term retrospective analysis was also done in accordance with the guidelines for epidemiologic study of the Japanese Ministry of Health, Labor and Welfare, and approved by the local ethics committee of our university.

\section{Electrophysiological examinations}

The nerve conduction studies were performed using MS6 (Medelec, Surrey, UK) and results were printed on photosensitive paper between 1981 and 1990. After that the data were recorded and analyzed on Viking (Nicole Biomedical, Madison, USA) from 1991 to 2002, or MEB2200 (Nihon-Koden, Tokyo, Japan) from 2003 to 2009.

We performed nerve conduction study (NCS) on the ulnar and tibial nerves. To record compound motor action potential (CMAP), the active recording electrodes were placed on the center of the muscle belly of the abductor digiti minimi muscle (ADM) and abductor hallucis (AH) and the references on the distal end of muscles. For motor nerve function, we stimulated the ulnar nerve at the wrist $(70 \mathrm{~mm}$ proximal from the active 
electrode placed on the ADM) and at the elbow, and tibial nerve at the internal malleolus (100 $\mathrm{mm}$ from the $\mathrm{AH}$ ) and the popliteal fossa. We measured and calculated the negative amplitude of CMAP, distal latency (DL), and the maximal motor nerve conduction velocity (MCV).

The maximal sensory nerve conduction velocity (SCV) was also measured on the ulnar and tibial nerves, recorded at the distal part of both nerves. Because we could not record sensory nerve action potential (SNAP) using the routine antidromic method with surface electrodes even in patients at an early stage of this disease, especially on the foot, we evaluated SCV using the orthodromic method with needle recording electrodes (the near-nerve method). The recording needle electrode was introduced very near the nerve at the wrist and internal malleolus, and the reference was placed subcutaneously $1 \mathrm{~cm}$ proximal to the active electrodes. To insulate needles near the nerve, we first stimulated the nerve with these two introduced electrodes. The needles were placed to evoke twitching on ADM or AH with weak stimulation (rectangular pulse of less than $0.6 \mathrm{~mA}$ with duration of $0.2 \mathrm{~ms}$ ). We stimulated nerves using ring electrodes placed on the fifth finger and the third toe, and averaged 50 - 1000 times. Although we could thus evaluate the SCV of the distal part of sensory nerve, the size of SNAP recorded with the antidromic near-nerve method was very variable with the recording conditions and was not suitable for quantitative comparison [28]. All electrophysiological parameters analyzed in this study were obtained when the subjects first visited our hospital, so they were not receiving any treatment including liver transplantation. We compared these indices with the clinical stages of FAP and duration of 
Kodaira et al. 8 of 26

illness. Statistical analysis was performed using the commercial software SigmaPlot11 (Systat, CA, USA) and Excel Toukei 2008 (Social Survey Research Information, Tokyo, Japan). 


\section{Results}

The clinical stages of FAP and changes in neurophysiological indices

The clinical stage in FAP patients advanced in parallel to the duration of their illness, but 67 of the 69 patients examined were in clinical stages I and II, so we paid attention to the changes in electrophysiological indices between the two groups. The duration of illness in patients at stage I was less than 4 years, while that in the majority of stage II patients was more than 4 years (Table 1 ).

In the ulnar nerve at stage I, the mean value of DL and MCV was almost at the normal limit and the size of CMAP was lower than the normal value in 5 of 35 patients. SCV was already decreased in many subjects. For tibial nerve function, the mean value of the size of CMAP, DL and MCV was less than the normal lower limit. SNAP of the tibial nerve had disappeared in 7 patients, although the mean value of SCV remained within the normal range (Table 1).

In stage II, all the indices in both nerves had deteriorated. The disappearance rate of CMAP and SNAP in the tibial nerve was 38\% and 50\% respectively (Table 1).

Duration of neuropathy and electrophysiological findings

CMAP on ADM was elicited in all patients except one. In the analysis of all the patients, CMAP on ADM was linearly correlated to duration of illness and declined 0.75 $\mathrm{mV} / \mathrm{y}(\mathrm{r}=0.64, \mathrm{p}<0.001$, Fig. $1 \mathrm{~A})$ : the decline in CMAP in males was $0.91 \mathrm{mV} / \mathrm{y}(\mathrm{r}=0.65$, $\mathrm{p}<0.001)$ and that in females was $0.60 \mathrm{mV} / \mathrm{y}(\mathrm{r}=0.61, \mathrm{p}<0.001)$, although there was no significant difference between the two genders $(\mathrm{p}=0.19)$. 
The decline in CMAP on AH was more obvious in relation to the duration of illness. It declined rapidly within the first 2 years after onset (Fig. 2A). CMAP completely disappeared in all the patients until 10 years (Fig. 3A). There were no differences in the disappearance rate of CMAP between the two genders.

Prolongation of DL in the ulnar nerve was linearly correlated to duration of illness ( $0.15 \mathrm{~ms} / \mathrm{y}, \mathrm{r}=0.40, \mathrm{p}<0.001$, Fig. 1B). DL in the ulnar nerve was prolonged by $0.25 \mathrm{~ms} / \mathrm{y}$ in males ( $\mathrm{r}=0.66, \mathrm{p}<0.001)$, but this tendency was not obvious in females ( $0.06 \mathrm{~ms} / \mathrm{y}, \mathrm{r}=0.17$, $\mathrm{p}=0.35)$.

The prolongation of DL in the tibial nerve was more apparent in relation to the duration of illness (Fig. 2B): it was prolonged by $0.32 \mathrm{~ms} / \mathrm{y}(\mathrm{r}=0.47, \mathrm{p}<0.001)$ in the analysis of all the patients. The slope was $0.48 \mathrm{~ms} / \mathrm{y}$ for males $(\mathrm{r}=0.56, \mathrm{p}<0.005)$ and $0.23 \mathrm{~ms} / \mathrm{y}$ for females $(\mathrm{r}=0.36, \mathrm{p}<0.05)$. This difference may indicate that disease progression in males was faster than in females, but this was not statistically significant $(\mathrm{p}=0.13)$.

Decrease in MCV in the ulnar nerve was linearly correlated to duration of illness, and the average decline was $1.7 \mathrm{~m} / \mathrm{s} / \mathrm{y}(\mathrm{r}=0.44, \mathrm{p}<0.001$, Fig $1 \mathrm{C})$ in the analysis of all the patients. MCV in males declined $2.9 \mathrm{~m} / \mathrm{s} / \mathrm{y}(\mathrm{r}=0.56, \mathrm{p}<0.001)$, but this tendency was not significant in females $(0.7 \mathrm{~m} / \mathrm{s} / \mathrm{y}, \mathrm{r}=0.28, \mathrm{p}=0.11)$.

The decline in MCV in the tibial nerve was more obvious in relation to the duration of illness. We could not measure MCV in most patients whose duration of illness was longer than 6 years, as shown in Fig. 2C.

We were able to measure SCV of the ulnar nerve in all the patients. In the analysis of 
the whole group, decrease in SCV in the ulnar nerve was linearly correlated to duration of illness, declining $1.1 \mathrm{~m} / \mathrm{s} / \mathrm{y}$ ( $\mathrm{r}=0.35, \mathrm{p}<0.005$, Fig. 1D). SCV in males declined $1.7 \mathrm{~m} / \mathrm{s} / \mathrm{y}$ $(\mathrm{r}=0.41, \mathrm{p}<0.05)$, but there was no such clear correlation between decline in SCV and duration of illness in females $(0.6 \mathrm{~m} / \mathrm{s} / \mathrm{y}, \mathrm{r}=0.31, \mathrm{p}=0.08)$.

It was very difficult to obtain SNAP in the tibial nerve in the FAP patients even using near-nerve recording. It could be obtained in most patients within the first 1 year after onset, but rapidly declined during the first 5 years (Fig. 2D, 3B). There were no differences in the occurrence of SNAP between males and females. Although the size of SNAP measured with needle electrodes is not suitable for statistical analysis [28], the size of SNAP in many patients was less than $0.5 \mu \mathrm{V}$. This indicated that the size of SNAP in the distal part of the tibial nerve was smaller than in normal subjects even in a very early stage of the disease as we were able to record SNAP of more than $5 \mu \mathrm{V}$ even in aged normal subjects. 


\section{Discussion}

The difference of age at onset in both genders

FAP patients originating from Ogawa village usually show an autosomal dominant trait with a high penetrance rate and equal sex distribution, and polyneuropathy and/or dysautonomia are common initial symptoms $[5,6]$. In our previous report 25 years ago, the mean age of onset was 33.4y for males and 34.2y for females, showing no difference between the genders [6]. However, in the present study it was 33.4y for males and 38.1y for females. We therefore did a subgroup analysis by dividing the patients into two groups. Although there was no difference for gender (male $37.2 \pm 11.2 \mathrm{y}$, female $41.5 \pm 9.4$, ns) among the patients examined before 1994, males tended to have earlier onset than females (male $30.1 \pm 6.2$, female $35.2 \pm 7.0, \mathrm{p}<0.05$ ) among the patients studied after 1995. This change of onset-age in male patients is explainable by genetic anticipation: this means younger onset and a more severe clinical picture in patients of successive generations. An anticipation phenomenon was reported to occur in FAP pedigrees originating from Portuguese [11], Swedish [12] and Japanese endemic foci $[13,14]$, and when the children are sons, the difference in age at onset seems to be significantly greater in the mother-son pairs than in father-son pairs [14]. It is, therefore, considered that male patients in Ogawa village have been affected by genetic anticipation during the past 25 years, showing earlier onset than females. Genetic anticipation has not been seen in sporadic FAP kindreds with a late-onset type of ATTRVal30Met, but this form of FAP predominantly involves males [10]. Thus, gender-related factors such as sex hormones have recently been surmised to play an important role in the development of FAP 
with ATTRVal30Met [29, 30].

Natural course of deteriorating peripheral nerve function on electrophysiology

This study indicated that all patients with ATTRVal30Met FAP related to this endemic focus lost electrophysiological activities in the tibial nerve within 10 years after onset but that ulnar nerve function was relatively preserved. Focal deposits of amyloid were shown to produce mechanical damage on peripheral nerves, causing length-dependent axonal degeneration [31]. It has been emphasized that predominant loss of unmyelinated and small myelinated nerve fibers is characteristic in the early stage of patients with ATTRVal30Met FAP related to endemic foci [32], and this selective involvement of peripheral nerve fibers is considered to be responsible for the appearance of various autonomic dysfunctions and dissociated sensory loss in these patients [32, 33].

Although unmyelinated nerve functions were not examined in this study, we quantitatively clarified large myelinated fiber mediated functions of FAP. In the case of sensory nerve function, routine conduction studies are carried out on the sural nerve at the calf, which is not the most distal part of the nerve. We tried to record SNAP on the very distal part of the peripheral nerve both in the leg and the hand. Although we could record SNAP of sural nerve at the ankle with stimulation at the calf in almost all FAP patients at stage 0 or I (size of SNAP raged $0.6-14.7 \mu \mathrm{V}$ ), we could evoke SNAP at the distal part of sural nerve in only $20 \%$ of patients at stage I (unpublished observation). We therefore tried to record SNAP using needle electrodes. It is essential to insert needle electrodes very near the nerve for recording. To place the electrodes near the nerve, we first stimulate the nerve with these 
inserted electrodes. Although normal subjects are able to feel very weak stimulation radiating in the sural nerve area and we can easily place electrodes in the proper position for sural nerve recording, the FAP patients could not feel such sensation. We therefore recorded on the tibial nerve, where we could navigate the electrodes by muscle twitching and record SNAP of less than $0.2 \mu \mathrm{V}$. In normal subjects we could evoke SNAP of more than $5 \mu \mathrm{V}$ from the distal part of tibial nerve and it was not so difficult for well-trained examiners to evoke very small SNAP in FAP patients.

The size of SNAP on the tibial nerve was very small even in patients in stage I, although the measurable SCV was normal in half of the patients. The disappearance of SNAP in the tibial nerve was observed in $20 \%$ of patients in stage I, and disappeared rather more rapidly than CMAP. Because a large fraction of SNAP amplitude reflects action potentials of large myelinated sensory nerve fibers [34], the reduction or disappearance of SNAP indicated considerable loss of large myelinated sensory nerve fibers even in patients in an early stage of the disease.

As for motor nerve function, there were more parameters available. DL and MCV reflect the function of the fastest, largest nerve fiber among myelinated fibers. When patients felt some neuropathic symptoms only in the leg (stage I), DL and MCV of the ulnar nerve were already disturbed in almost half of the patients. DL in the tibial nerve was significantly prolonged in patients at stage II. These findings suggested the presence of segmental demyelination in the distal part of peripheral nerve in addition to axonal degeneration in ATTRVal30Met FAP, which was shown histopathologically [33, 35]. 
The size of CMAP reflects the number of innervated muscle fibers, and thus both denervation and reinnervation processes change the size of CMAP. If the reinnervation process is active, the size of CMAP underestimates the disease progress. This parameter therefore reflects whole peripheral motor functions which contain relatively smaller motor nerve fibers than DL or MCV. The size of CMAP on AH was less than the normal value in $63 \%$ of patients even in stage I. CMAP on ADM was also obviously reduced in $14 \%$ of patients in stage I. Although the size of CMAP on ADM was linearly reduced with the course of the disease (Fig 1A), the CMAP on AH decreased more rapidly within the first 2 years (Fig2A). These findings indicated that motor function of the foot in the patients with this disease rapidly deteriorated within the first 2 years, although we were able to record small CMAP in many patients for a longer duration (Fig 3A).

The size of CMAP therefore seems to be a better parameter for following peripheral motor nerve function in patients with FAP rather than MCV of DL, and this is compatible with the histopathological findings. Tibial nerve dysfunction was considerably different between stage I and II. In stage II, CMAP on AH and SNAP of the tibial nerve could not be evoked in about half of the patients, and the duration of illness leading to stage II was almost 4 or 5 years after onset.

DL, MCV and SCV in ulnar nerve declined more slowly than CMAP and those parameters in tibial nerve. As for the difference of progression according to gender, DL, MCV and SCV in the ulnar nerve declined linearly with the duration of illness in males, but this was not so obvious in females. These findings in ulnar nerve are associated with the 
difficulty in evaluating the disease progression of axonal neuropathy by these parameters which indicate nerve conduction delay. On the other hand, these observations indicate relatively rapid disease progress in males. The prolongation of DL in the tibial nerve also tended to be more marked in males than in females. These findings are possibly ascribable to genetic anticipation as discussed above. Such male predominance was recently observed in TTR-amyloid cardiomyopathy in older Swedish patients with ATTR Val30Met FAP[36]. Difference in pathophysiology between endemic- versus non-endemic patients

In FAP with ATTRVal30Met it has been shown that the clinical picture and the histopathological and electrophysiological findings of peripheral nerve lesions are considerably different between patients with early-onset type and those with late-onset type [10, 15-17]: the latter group of patients frequently has serious cardiac involvement [37], and upper limb neuropathy may develop at an earlier stage of the disease than previously recognized [38, 39]. Histopathology of dorsal root ganglia shows a more selective loss of small neurons in early-onset patients [40], while loss of neurons of all sizes is seen in late-onset patients [15]. The amount of amyloid deposition in nerve tissues including the entire length of the peripheral nerves, dorsal root and sympathetic ganglia is greater in early-onset patients [40], while in late-onset patients the accumulation of Congo-red-negative but TTR-immunoreactive non-fibrillar protein is abundant in these tissues [17]. This pathologic amyloid-related protein deposition consists of both variant and wild type TTR [41], the latter being predominant in the involved tissues in late-onset patients [17]. These findings indicate that the underlying pathogenetic mechanism of amyloid neuropathy differs between 
both types. In patients with early-onset type the formation and deposition of amyloid fibrils are rapid, while those with late-onset type might have a long asymptomatic period in which peripheral nerves are gradually damaged by accumulation of non-fibrillar TTR protein [17].

It is now thought that TTR-derived amyloid deposits in vivo are not always stable and can turn over dynamically [23]. Thus, useful therapies including liver transplantation can change the clinical courses of FAP patients. The vast majority of FAP patients who were successfully treated by liver transplantation were ATTR Val30Met type with early onset [42, 43]. To determine the severity of neuropathy or therapeutic effects in these FAP patients, a detailed electrophysiological study is most valuable. Our present study has provided a base of electrophysiological data for peripheral nerve dysfunction in the early-onset type of ATTR Val30Met FAP patients of endemic origin. 


\section{Acknowledgments}

We greatly appreciate Ms. T. Asawa's technical assistance through the whole period of this study. This work was supported by a grant from Amyloid Research Committee, the Ministry of Public Health, Labor and Welfare, Japan and a Group Research Grant for the Pathogenesis and Therapy for Intractable Neuropathy in Japan.

\section{Declaration of interest}

The authors report no conflicts of interest. 


\section{References}

1 Ikeda S, Nakazato M, Ando Y, Sobue G.. Familial transthyretin-type amyloid polyneuropathy in Japan: clinical and genetic heterogeneity. Neurology 2002; 58:1001-1007.

2 Andrade C. A peculiar form of peripheral neuropathy: familial atypical generalized amyloidosis with special involvement of the peripheral nerves. Brain 1952; 75:408-427.

3 Andersson R. Familial amyloidosis with polyneuropathy. Acta Med Scand 1970; 50:85-94.

4 Araki S, Mawatari S, Ohta M, Nakajima A, Kuroiwa Y. Polyneuritic amyloidosis in a Japanese family. Arch Neurol 1968; 18:593-602.

5 Kito S, Itoga E, Kamiya K, Kishida T, Yamamura Y. Studies on familial amyloid polyneuropathy in Ogawa Village, Japan. Eur Neurol 1980; 19:141-151.

6 Ikeda S, Hanyu N, Hongo M, Yoshioka J, Oguchi H, Yanagisawa N, Kobayashi T, Tsukagoshi H, Ito N, Yokota T. Hereditary generalized amyloidosis with polyneuropathy. Clinicopathological study of 65 Japanese patients. Brain 1987; 110:315-337.

7 Connors LH, Lim A, Prokaeva T, Roskens VA, Costello CE. Tabulation of human transthyretin (TTR) variants, 2003. Amyloid 2003; 10:160-184.

8 Benson MD, Kincaid JC. The molecular biology and clinical features of amyloid neuropathy. Muscle Nerve 2007; 36:411-423.

9 Misu K, Hattori N, Nagamatsu M, Ikeda S, Ando Y, Nakazato M, Takei Y, Hanyu N, Usui Y, Tanaka F, Harada T, Inukai A, Hashizume Y, Sobue G. Late-onset familial amyloid polyneuropathy type I (transthyretin Met30-associated familial amyloid 
polyneuropathy) unrelated to endemic focus in Japan. Clinicopathological and genetic features. Brain 1999; 122:1951-1962.

10 Koike H, Misu K, Ikeda S, Ando Y, Nakazato M, Ando E, Yamamoto M, Hattori N, Sobue G. Study Group for Hereditary Neuropathy in Japan.Type I (transthyretin Met30) familial amyloid polyneuropathy in Japan: early- vs late-onset form. Arch Neurol 2002; 59:1771-1776.

11 Sousa A, Coelho T, Barros J, Sequeiros J. Genetic epidemiology of familial amyloidotic polyneuropathy (FAP)-type I in Póvoa do Varzim and Vila do Conde (north of Portugal). Am J Med Genet 1995; 60:512-521.

12 Drugge U, Andersson R, Chizari F, Danielsson M, Holmgren G, Sandgren O, Sousa A. Familial amyloidotic polyneuropathy in Sweden: a pedigree analysis. J Med Genet 1993; 30:388-392.

13 Tashima K, Ando Y, Tanaka Y, Uchino M, Ando M. Change in the age of onset in patients with familial amyloidotic polyneuropathy type I. Intern Med 1995; 34:740-750.

14 Yamamoto K, Ikeda S, Hanyu N, Takeda S, Yanagisawa N. A pedigree analysis with minimized ascertainment bias shows anticipation in Met30-transthyretin related familial amyloid polyneuropathy. J Med Genet 1998; 35:23-30.

15 Koike H, Misu K, Sugiura M, Iijima M, Mori K, Yamamoto M, Hattori N, Mukai E, Ando Y, Ikeda S, Sobue G. Pathology of early- vs late-onset TTR Met30 familial amyloid polyneuropathy. Neurology 2004; 63:129-138.

16 Koike H, Kawagashira Y, Iijima M, Yamamoto M, Hattori N, Tanaka F, Hirayama M, Ando Y, Ikeda S, Sobue G. Electrophysiological features of late-onset transthyretin Met30 familial amyloid polyneuropathy unrelated to endemic foci. J Neurol 2008; 
255:1526-1533.

17 Koike H, Ando Y, Ueda M, Kawagashira Y, Iijima M, Fujitake J, Hayashi M, Yamamoto M, Mukai E, Nakamura T, Katsuno M, Hattori N, Sobue G. Distinct characteristics of amyloid deposits in early- and late-onset transthyretin Val30Met familial amyloid polyneuropathy. J Neurol Sci 2009; 287:178-184.

18 Soprano DR, Herhert J, Soprano KJ, Schon EA, Goodman DS. Demonstration of transthyretin mRNA in the brain and other extrahepatic tissues. J Biol Chem 1985; 260:11793-11798.

19 Holmgren G, Steen L, Ekstedt J, Groth CG, Ericzon BG, Eriksson S, Andersen O, Karlberg I, Nordén G, Nakazato M et al. Biochemical effect of liver transplantation in two Swedish patients with familial amyloidotic polyneuropathy (FAP-met ${ }^{30}$ ). Clin Genet 1991; 40:242-246.

20 Shimojima Y, Morita H, Kobayashi S, Takei Y, Ikeda S. Ten-year follow-up of peripheral nerve function in patients with familial amyloid polyneuropathy after liver transplantation. J Neurol 2008; 255:1220-1225.

21 Jonsén E, Suhr OB, Tashima K, Athlin E. Early liver transplantation is essential for familial amyloidotic polyneuropathy patients’ quality of life. Amyloid 2001; 8:52-57.

22 Suhr OB, Friman S, Ericzon BG. Early liver transplantation improves familial amyloidotic polyneuropathy patients’ survival. Amyloid 2005; 12:233-238.

23 Tsuchiya A, Yazaki M, Kametani F, Takei Y, Ikeda S. Marked regression of abdominal fat amyloid in patients with familial amyloid polyneuropathy during long-term follow-up after liver transplantation. Liver Transpl 2008; 14:563-570. 
24 Tojo K, Sekijima Y, Kelly JW, Ikeda S. Diflunisal stabilizes familial amyloid polyneuropathy-associated transthyretin variant tetramer in serum against dissociation required for amyloidogenesis. Neurosci Res 2006; 56:441-449.

25 Ikeda S, Nakano T, Yanagisawa N, Nakazato M, Tsukagoshi H. Asymptomatic homozygous gene carrier in a family with type I familial amyloid polyneuropathy. Eur Neurol 1992; 32:308-313.

26 Tachibana N, Tokuda T, Yoshida K, Taketomi T, Nakazato M, Li YF, Masuda Y, Ikeda S. Usefulness of MALDI/TOF mass spectrometry of immunoprecipitated serum variant transthyretin in the diagnosis of familial amyloid polyneuropathy. Amyloid 1999; 6:282-288.

27 Countinho P, Salva M, Lima JL, Barbosa AR. Forty years of experience with type I amyloid neuropathy: review of 483 cases. In: Glenner GG, Costa PP, Freitas F, editors. Amyloid and Amyloidosis. Amsterdam: Excepta Medica; 1980. p88-98.

28 Buchthal F, Rosenfalck A. Evoked action potentials and conduction velocity in human sensory nerves. Brain Res 1966; 3:1-122.

29 Gonçalves I, Alves CH, Quintela T, Baltazar G, Socorro S, Saraiva MJ, Abreu R, Santos CR. Transthyretin is up-regulated by sex hormones in mice liver. Mol Cell Biochem 2008; 317:137-142.

30 Rapezzi C, Riva L, Quarta CC, Perugini E, Salvi F, Longhi S, Ciliberti P, Pastorelli F, Biagini E, Leone O, Cooke RM, Bacchi-Reggiani L, Ferlini A, Cavo M, Merlini G, Perlini S, Pasquali S, Branzi A. Gender-related risk of myocardial involvement in systemic amyloidosis. Amyloid 2008; 15:40-48. 
31 Said G, Ropert A, Faux N. Length-dependent degeneration of fibers in Portuguese amyloid polyneuropathy: a clinicopathologic study. Neurology 1984; 34:1025-1032.

32 Dyck PJ, Lambert EH. Dissociated sensation in amyloidosis. Compound action potential, quantitative histologic and teased-fiber, and electron microscopic studies of sural nerve biopsies. Arch Neurol 1969; 20:490-507.

33 Hanyu N, Ikeda S, Nakadai A, Yanagisawa N, Powell HC. Peripheral nerve pathological findings in familial amyloid polyneuropathy: a correlative study of proximal sciatic nerve and sural nerve lesions. Ann Neurol 1989; 25:340-350.

34 Krarup C. Compound sensory action potential in normal and pathological human nerves. Muscle Nerve 2004; 29:465-83.

35 Planté-Bordeneuve V, Ferreira A, Lalu T, Zaros C, Lacroix C, Adams D, Said G. Diagnostic pitfalls in sporadic transthyretin familial amyloid polyneuropathy (TTR-FAP). Neurology 2007; 69:693-698.

36 Hörnsten R, Pennlert J, Wiklund U, Lindqvist P, Jensen, SM, Suhr O. Heart complications in familial transthyretin amyloidosis: impact of ange and gender. Amyloid 2010; 17:63-68.

37 Hattori T, Takei Y, Koyama J, Nakazato M, Ikeda S. Clinical and pathological studies of cardiac amyloidosis in transthyretin type familial amyloid polyneuropathy. Amyloid 2003; 10:229-239.

38 Koike H, Morozumi S, Kawagashira Y, Iijima M, Yamamoto M, Hattori N, Tanaka F, Nakamura T, Hirayama M, Ando Y, Ikeda S, Sobue G.. The significance of carpal tunnel syndrome in transthyretin Val30Met familial amyloid polyneuropathy. Amyloid 2009; 16:142-148. 
39 Tojo K, Tsuchiya-Suzuki A, Sekijima Y, Morita H, Sumita N, Ikeda S. Upper limb neuropathy such as carpal tunnel syndrome as an initial manifestation of ATTR Val30Met familial amyloid polyneuropathy. Amyloid 2010; 17:32-35.

40 Sobue G, Nakao N, Murakami K, Yasuda T, Sahashi K, Mitsuma T, Sasaki H, Sakaki Y, Takahashi A. Type I familial amyloid polyneuropathy. A pathological study of the peripheral nervous system. Brain 1990; 113:903-919.

41 Yazaki M, Mitsuhashi S, Tokuda T, Kametani F, Takei Y, Koyama J, Kawamorita A, Kanno H, Ikeda SI. Progressive wild-type transthyretin deposition after liver transplantation preferentially occurs onto myocardium in FAP patients. Am J Transplnat 2007; 7:235-242.

42 Yamamoto S, Wilczek HE, Nowak G, Larsson M, Oksanen A, Iwata T, Gjertsen H, Söderdahl G, Wikström L, Ando Y, Suhr OB, Ericzon BG. Liver transplantation for familial amyloidotic polyneuropathy (FAP): a single-center experience over 16 years. Am J Transplant 2007; 7:2597-2604.

43 Familial Amyloidotic Polyneuropathy World Transplant Registry. Domino Liver Transplant Registry. Available from: http://www.fapwtr.org. Accessed December 62010. 


\section{Figure 1}

Changes in CMAP (A), DL (B), MCV (C) and SCV (D) from the onset of neuropathy in ulnar nerve.

Filled circle indicats male and white female. Solid line shows regression line and dotted line indicates limitation of normal value of each parameter. When CMAP or SNAP disappeared, the size of potential was expressed as zero, and the conduction velocity as immeasurable (IM).

\section{Figure 2}

Changes in CMAP (A), DL (B), MCV (C) and SCV (D) from the onset of neuropathy in

\section{tibial nerve.}

Each mark represents male (filled circle) and female (white circle). Dotted line indicates limitation of normal value of each parameter. In B, DL in tibial nerve was linearly correlated to duration of neuropathy. Males (solid line) tended to progress faster than females (dashed line) but not statistically significant. 


\section{Figure 3}

Occurrence of CMAP on AH (A) and SNAP in tibial nerve (B) using Kaplan-Meier curve.

Solid black line indicates data for all subjects, gray solid line males, and dashed line females.

A: CMAP of AH started to disappear from 3 years after onset of neuropathy. CMAP on AH

had disappeared in half of the patients at 7.7 years and in almost all patients at 10 years.

Gender difference in the disappearance of CMAP was not detected.

B: SNAP in tibial nerve started to disappear from 1 year after onset of neuropathy. SNAP in

tibial nerve had disappeared in half of the patients at 6.5 years and in almost all patients at 10 years. Gender difference in the disappearance of SNAP was not detected. 
Table 1 Clinical stage and parameters of nerve conduction study

\begin{tabular}{|c|c|c|c|c|c|}
\hline Clinical stage & Stage $0(n=2)$ & Stage I $(\mathrm{n}=35)$ & Stage II $(n=32)$ & Normal value & $\begin{array}{c}\text { Statistical difference } \\
\text { between stage I and II }\end{array}$ \\
\hline $\begin{array}{c}\text { Duration of neuropathy (years) } \\
\text { mean } \pm \text { sd }\end{array}$ & $1.5 \pm 0.7$ & $2.3 \pm 1.6$ & $5.1 \pm 2.2$ & & $\mathrm{p}<0.001 *$ \\
\hline \multicolumn{6}{|l|}{ Ulnar nerve } \\
\hline \multicolumn{6}{|l|}{ CMAP (mV) } \\
\hline $\begin{array}{c}\text { mean } \pm \text { sd } \\
\text { Disappearance rate }\end{array}$ & $\begin{array}{c}7.9 \pm 4.1 \\
0 \%\end{array}$ & $\begin{array}{c}6.7 \pm 1.9 \\
0 \%\end{array}$ & $\begin{array}{c}3.0 \pm 2.5 \\
3 \%\end{array}$ & $>4.9$ & $\begin{array}{c}\mathrm{p}<0.001^{*} \\
\mathrm{~ns} \dagger\end{array}$ \\
\hline $\begin{array}{l}\text { DL (ms) } \\
\quad \text { mean } \pm \text { sd }\end{array}$ & $3.3 \pm 0.4$ & $3.4 \pm 0.9$ & $3.9 \pm 1.1 \ddagger$ & $<3.2$ & $\mathrm{p}=0.11 *$ \\
\hline $\begin{array}{l}\operatorname{MCV}(\mathrm{m} / \mathrm{s}) \\
\quad \text { mean } \pm \mathrm{sd}\end{array}$ & $55.3 \pm 2.1$ & $55.6 \pm 5.2$ & $50.2 \pm 7.8 \ddagger$ & $>55$ & $\mathrm{p}<0.01^{*}$ \\
\hline $\operatorname{SCV}(\mathrm{m} / \mathrm{s})$ & & & & & \\
\hline $\begin{array}{c}\text { mean } \pm \text { sd } \\
\text { Disappearance rate }\end{array}$ & $\begin{array}{c}50.4 \pm 0.6 \\
0 \%\end{array}$ & $\begin{array}{c}46.2 \pm 4.8 \\
0 \%\end{array}$ & $\begin{array}{c}42.8 \pm 9.8 \\
0 \%\end{array}$ & $>50$ & $\begin{array}{l}\mathrm{ns} * \\
\mathrm{~ns} \dagger\end{array}$ \\
\hline \multicolumn{6}{|l|}{ Tibial nerve } \\
\hline \multicolumn{6}{|l|}{ CMAP $(\mathrm{mV})$} \\
\hline $\begin{array}{c}\text { mean } \pm \text { sd } \\
\text { Disappearance rate }\end{array}$ & $\begin{array}{c}8.7 \pm 0.5 \\
0 \%\end{array}$ & $\begin{array}{c}5.3 \pm 4.5 \\
3 \%\end{array}$ & $\begin{array}{c}0.9 \pm 1.9 \\
38 \%\end{array}$ & $>6.2$ & $\begin{array}{l}\mathrm{p}<0.001^{*} \\
\mathrm{p}<0.001 \dagger\end{array}$ \\
\hline $\begin{array}{l}\mathrm{DL}(\mathrm{ms}) \\
\quad \text { mean } \pm \mathrm{sd}\end{array}$ & $4.4 \pm 0.3$ & $5.2 \pm 1.3^{*}$ & $6.5 \pm 1.8 \ddagger$ & $<5.0$ & $\mathrm{p}<0.005^{*}$ \\
\hline $\begin{array}{l}\mathrm{MCV}(\mathrm{m} / \mathrm{s}) \\
\text { mean } \pm \mathrm{sd}\end{array}$ & $42.7 \pm 3.7$ & $41.8 \pm 4.3^{*}$ & $39.1 \pm 5.4 \ddagger$ & $>45$ & $\mathrm{p}<0.05^{*}$ \\
\hline $\mathrm{SCV}(\mathrm{m} / \mathrm{s})$ & & & & & \\
\hline $\begin{array}{c}\text { mean } \pm \text { sd } \\
\text { Disappearance rate }\end{array}$ & $\begin{array}{l}41.8^{*} \\
50 \%\end{array}$ & $\begin{array}{c}36.0 \pm 5.8^{*} \\
20 \%\end{array}$ & $\begin{array}{c}31.1 \pm 10.1 \ddagger \\
50 \%\end{array}$ & $>35$ & $\begin{array}{l}\mathrm{p}=0.06^{*} \\
\mathrm{p}<0.01 \dagger\end{array}$ \\
\hline
\end{tabular}


Clinical stages of FAP as defined by Countinho et al. (1980)[27].

Stage 0: patients have some autonomic dysfunction but lack polyneuropathic symptoms or signs.

Stage I: polyneuropathy is localized to lower limbs, and patients can walk without help.

Stage II: polyneuropathy involves upper and lower limbs; patients are handicapped but can still walk with help.

Stage III: severe polyneuropathy and autonomic dysfunction confines patients to wheelchair, or they are bedridden.

* P-value of students' t-test

$\dagger \mathrm{P}$-value of chi-square test

$\ddagger$ Parameters were calculated only from patients in whom CMAP and SNAP could be detected.

ns: not significant 

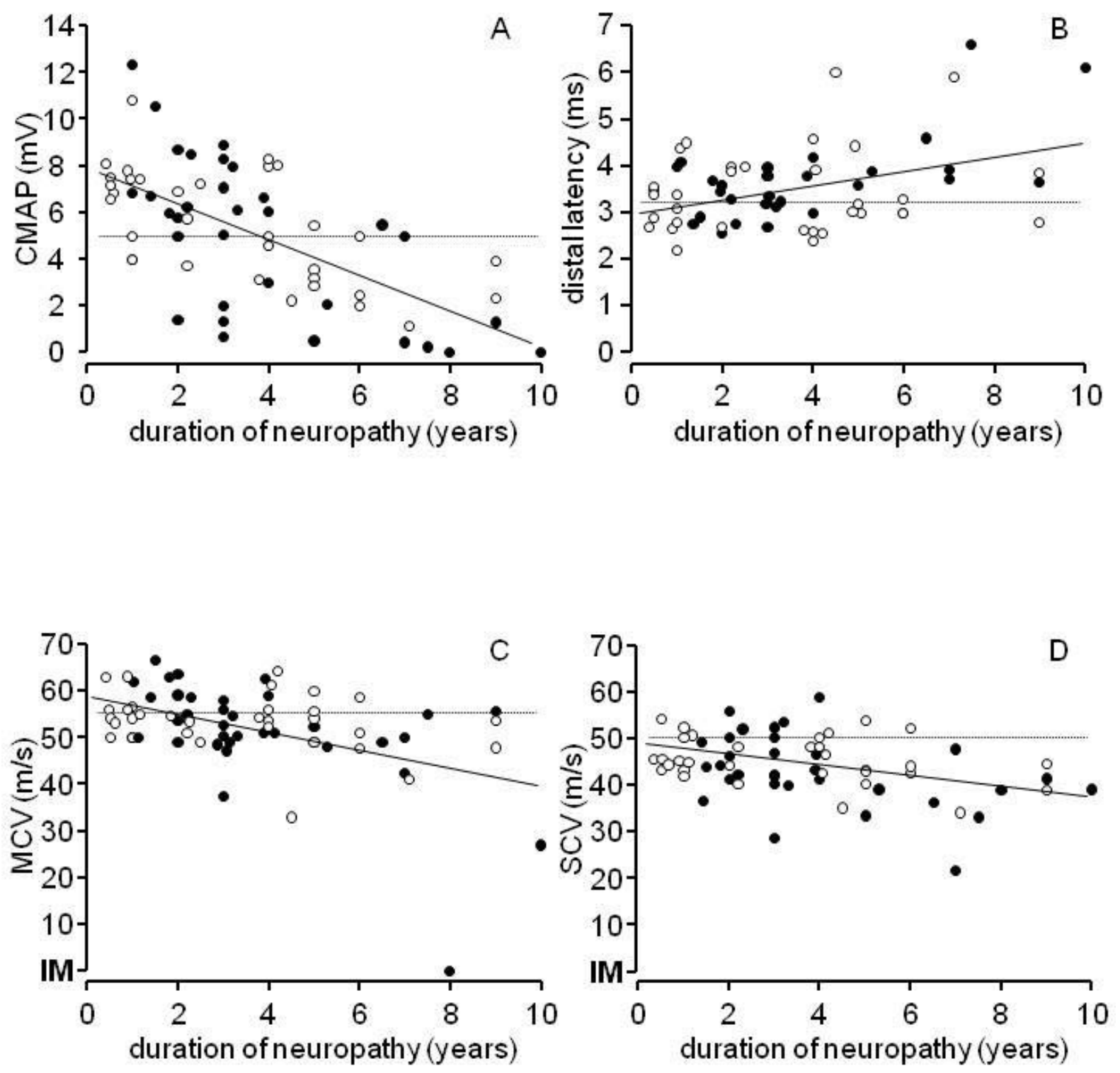

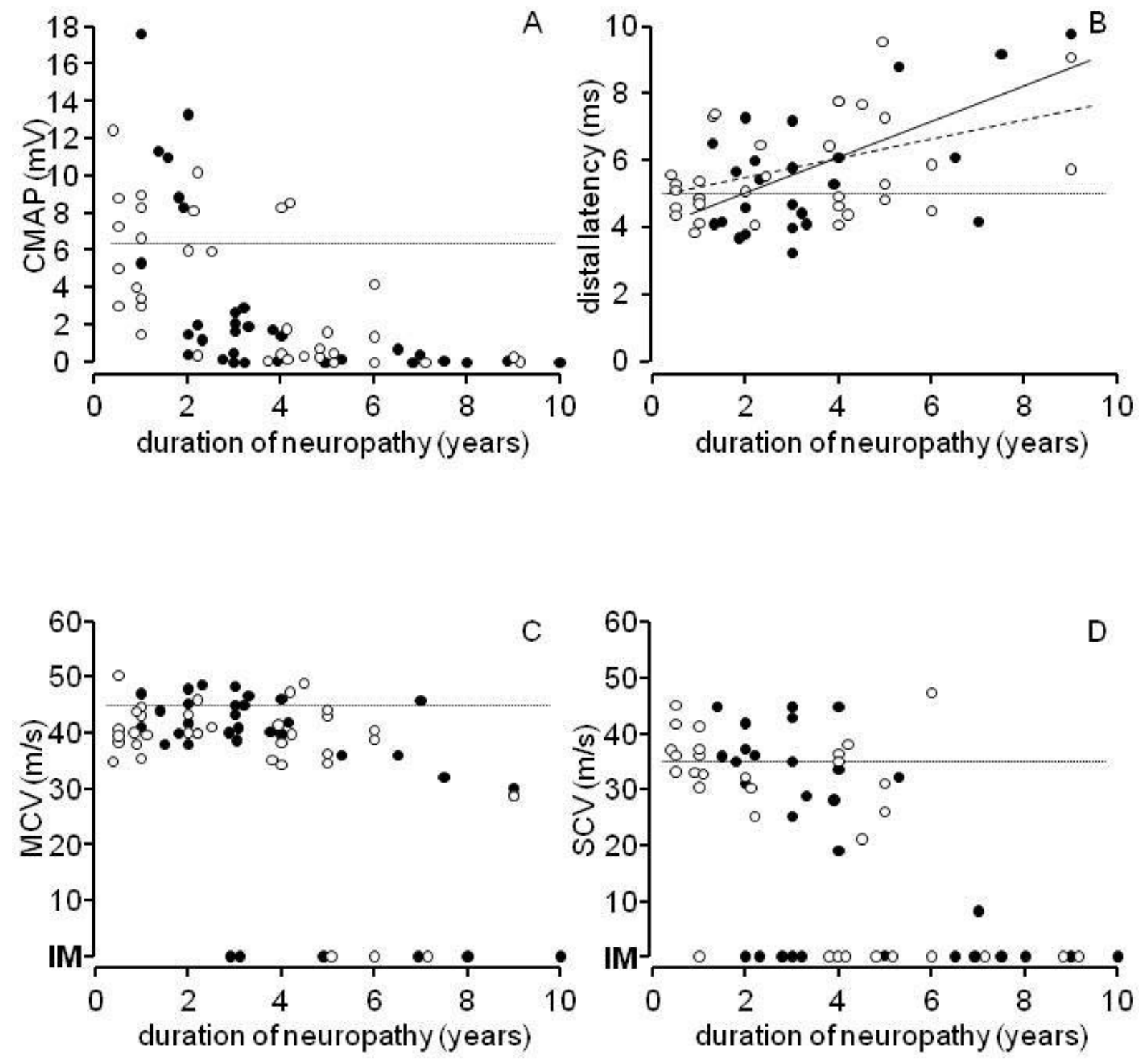

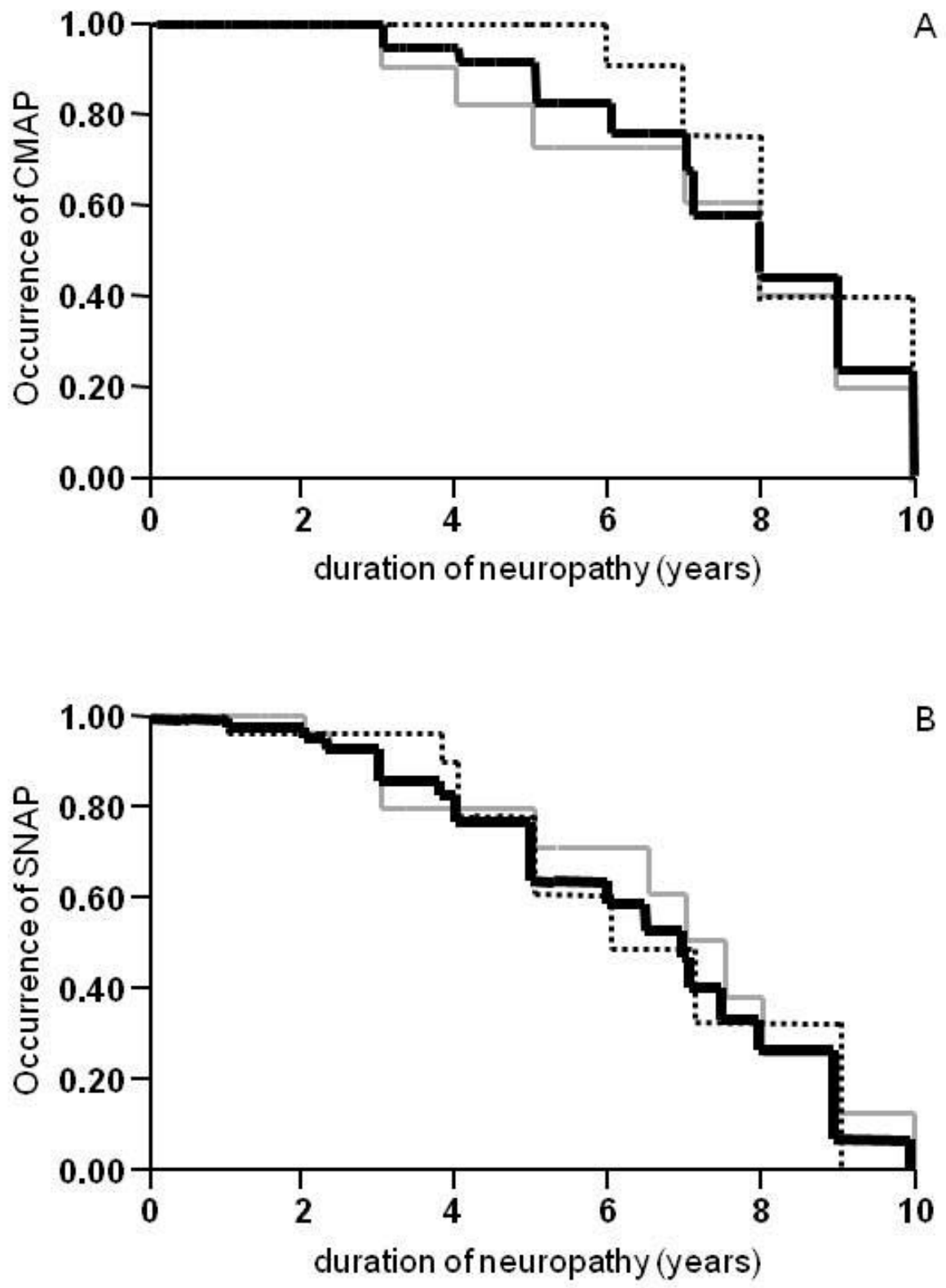